\title{
Proximal chiasmata induce non-disjunctional orientation of Robertsonian trivalents in a grasshopper
}

\author{
PATRICIA M. MIROL* $\ddagger \&$ CLAUDIO J. BIDAU†‡ \\ Laboratorio de Genética, Departamento de Ciencias Biológicas, Facultad de Ciencias Exactas y Naturales, Universidad \\ de Buenos Aires, Ciudad Universitaria, 1428, Buenos Aires, República Argentina, †Departamento de Genética, Facultad \\ de Ciencias Exactas, Quimicas y Naturales, Universidad Nacional de Misiones, Félix de Azara 1552, 6 piso, 3300, \\ Posadas, Misiones, República Argentina
}

\begin{abstract}
The relationship between the symmetry of the meiotic configuration and the type of meiotic orientation (disjunctional and non-disjunctional) in Robertsonian trivalents of Dichroplus pratensis (Melanoplinae, Acrididae) was analysed. The results indicate, first, that neither chromosomal size nor the relation between the length of the chromosomes involved in each fusion are important factors for the determination of the orientation. Second, chiasmata localization, which in turn determines effective inter-centromeric distance, may be central. A high positive correlation between proximal chiasma frequency and non-disjunctional orientation at Prometaphase I and Metaphase I was found. These results are in agreement with the hypothesis that the shorter the inter-centromeric distance the greater is the probability that both centromeres migrate to the same pole. The importance of these results is also discussed in relation to the stability of the polymorphisms in this species.
\end{abstract}

Keywords: chiasmata, grasshopper, non-disjunction, Robertsonian translocation.

\section{Introduction}

The analysis of the factors that affect meiotic orientation and segregation of configurations, which result from heterozygous chromosomal rearrangements, is of great interest to our understanding of many cytogenetic and evolutionary problems. The elucidation of the relative incidence and operative mechanisms of those factors is relevant to the assessment of the potential decrease in fertility brought about by the rearrangements in heterozygous carriers. This is of central interest for determining the impact of chromosome mutations in humans, domestic animals and plants.

Furthermore, many chromosomal models of speciation have been put forward and an adaptative role of chromosomal rearrangements has frequently been proposed (White, 1978; Baker \& Bickham, 1986; King, 1987; Sites \& Moritz, 1987; Bidau, 1989, 1991). Therefore, note that a rearrangement which may be central in the generation of post-mating isolation, can

*Correspondence. $\ddagger$ Both authors are affiliated to the CONICET (Argentina). also be found, with some exceptions, as a balanced polymorphism in natural populations.

Thus, one may ask which circumstances and factors determine that such structural changes follow such different evolutionary pathways.

Many works on plants and animals have been devoted to the study of factors that affect and modify the meiotic behaviour of structural rearrangements (Sybenga, 1975; Rickards, 1977; 1983; Wise \& Rickards, 1977; John, 1987; Sybenga \& Rickards, 1987; Bidau \& Mirol, 1988). Their potential ability to produce negative heterosis through imbalanced segregation is their principal quality relative to speciation (King, 1987).

In the case of translocation (Robertsonian or reciprocal) heterozygotes such behaviour is ruled by factors such as inter-centromere distance, size of the involved chromosomes, the initial position of the configuration in the meiotic cell, the premeiotic disposition of chromosomes, the relative time of centromere activation, the number and position of chiasmata and the genetic background (Rickards, 1983; Narasinga Rao \& Sybenga, 1984; Arundhati et al., 1986; John, 
1987; Sybenga \& Rickards, 1987). These factors, jointly with selective and stochastic processes, are responsible for the fate of a given chromosomal rearrangement in a natural population.

The symmetry of the translocation multiple, of all factors, seems significant in the above respect. Symmetry is determined by the interaction of three factors: size of the chromosomes, inter-centromeric distance and frequency and localization of chiasmata; the latter being the most relevant (Rickards, 1983).

Despite the large number of works on these problems, only a few provide statistical evidence on the effects of chiasma frequency and position on multiple orientation (Rees \& Sun, 1965; Diez \& Puertas, 1984; Cabrero \& Camacho, 1985; Arana et al., 1987a, b; Cano \& Santos, 1990), and, if statistical evidence exists, in general it reflects the relation between chiasma frequency and orientation. Most papers, however, suggest the existence of such a correlation and the relationship between chromosome change and chiasma change is well documented (Sybenga, 1975; Arana et al., 1982; Rickards, 1983; John, 1987; Parker, 1987; Bidau, 1990).

On this basis, it is worth analysing how the position of chiasmata can exert influence on the orientation of multiples. It is clear that the more proximal the position of a chiasma, the shorter the distance between pairs of centromeres that should co-orientate.

In this paper we study a cytogenetically favourable material, a species polymorphic for several Robertsonian translocations (see Materials and Methods), in which a correlation between symmetry and orientation of multiples is sought. A strong albeit quantitative correlation, between orientation and chiasma position could give support to one or other of the different hypotheses that have been put forward regarding the effect of chiasmata on orientation (see Discussion). Further factors that affect multivalent behaviour are analysed in a forthcoming paper.

Table 1 Karyomorphs of the 49 males of Dichroplus pratensis analysed with their localities and years of capture. (Ht: heterozygote, H: structural homozygote, S: unfused chromosomes). For references to localities and fusion frequencies, see Tosto \& Bidau, 1991 (figs 3 and 4) and Bidau, 1984 (table X)

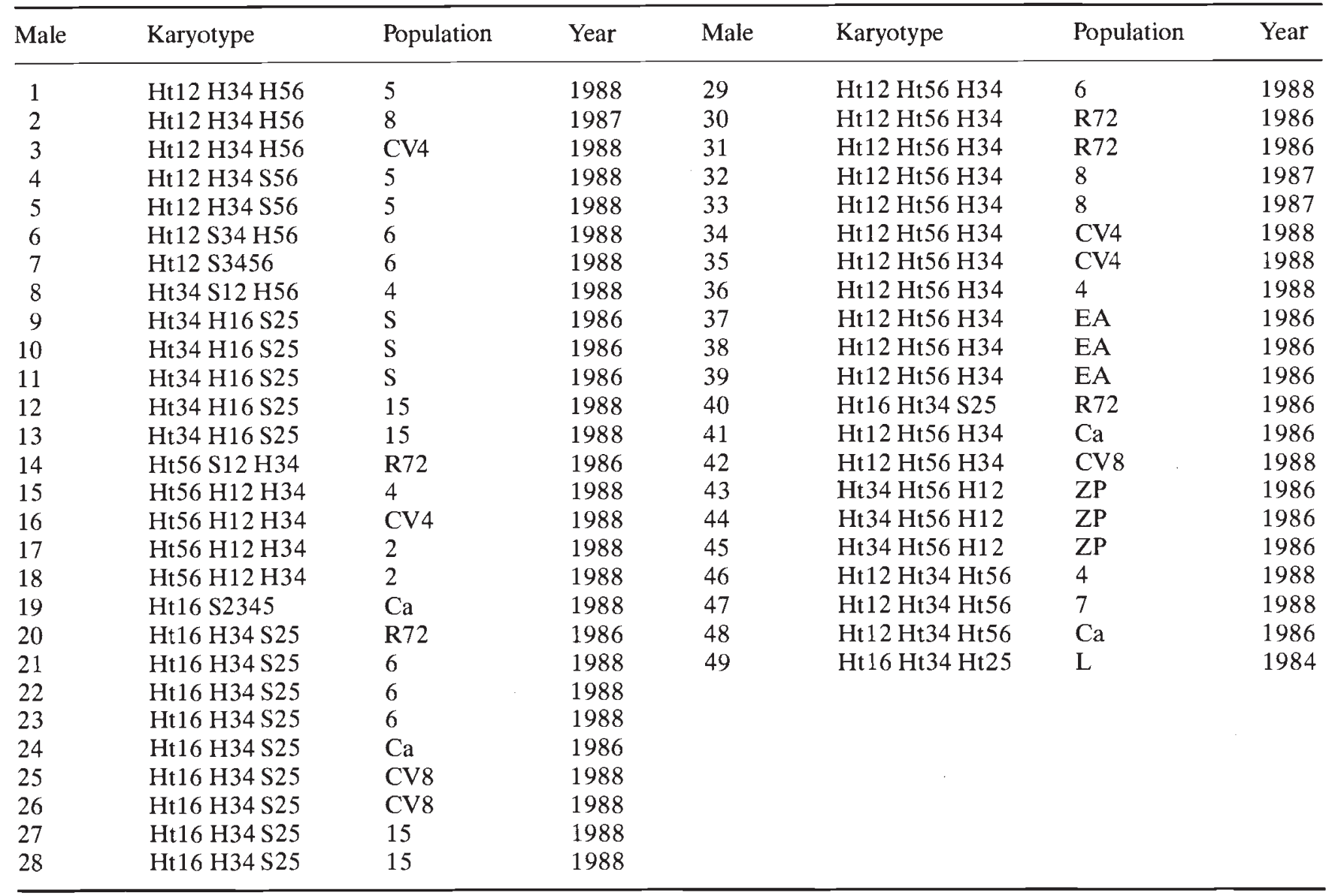




\section{Materials and methods}

Forty-nine selected $D$. pratensis males were selected for this study and collected in 1984, 1986, 1987 and 1988 at several localities of Sierra de la Ventana (Buenos Aires Province, Argentina). All males were heterozygous for one (28), two (17) or three (4) centric fusions. These individuals are described in Table 1 ,

Table 2 Relative length $(\mathrm{RL})$ and arm ratio $(\mathrm{AR})$ of the four metacentric chromosomes under study

\begin{tabular}{lll}
\hline Fusion & RL $(\%)$ & AR \\
\hline 1.2 & 32.52 & $0.86 \pm 0.02$ \\
3.4 & 25.88 & $0.91 \pm 0.02$ \\
5.6 & 20.65 & $0.87 \pm 0.02$ \\
1.6 & 27.57 & $0.55 \pm 0.02$ \\
\hline
\end{tabular}

regarding locality, date of capture and karyotype. The four polymorphic fusions analysed are 1/2, 3/4, 5/6 and $1 / 6$, which occur at varying frequencies in different populations. Testis follicles fixed in 3:1 (methanol: acetic) were squashed for meiotic analysis in lactopropionic orcein. Twenty-five metaphase I (MI) cells and 25 prometaphase I (PMI) cells were scored for each male. The criteria for distinguishing PMI and MI stages are described in Bidau \& Mirol (1988). In both stages chiasmata were scored in each trivalent and classified as proximal (P), interstitial (I) or distal (D) as in Bidau (1990) (see Fig. 1). In addition, two measurements were calculated for each trivalent: the arm ratio $(A R=$ short arm length/long arm length $)$ of the metacentric and the relative length $(R L)$ of the involved chromosomes; the latter was calculated as a percentage of the total haploid genome length. These measurements are shown in Table 2.

Table 3 Percentage of proximal $(\mathbf{P})$, interstitial $(\mathrm{I})$ and distal $(\mathrm{D})$ chiasmata in simple heterozygotes of $D$. pratensis. The chiasmata were counted without discriminating between convergent and non-convergent orientation types. The data correspond to PMI and MI stages

\begin{tabular}{|c|c|c|c|c|c|c|c|c|}
\hline \multirow[b]{2}{*}{ Male } & \multicolumn{4}{|c|}{ Metaphase I } & \multicolumn{4}{|c|}{ Prometaphase I } \\
\hline & $\% \mathrm{NCO}$ & $P$ & I & $\mathrm{D}$ & $\% \mathrm{NCO}$ & $P$ & I & D \\
\hline 8 & 4 & 5.88 & 25.49 & 68.63 & 16 & 9.80 & 19.61 & 70.59 \\
\hline 4 & 4 & 4 & 24 & 72 & 12 & 6 & 30 & 64 \\
\hline 10 & 4 & 6 & 18 & 76 & 8 & 6.25 & 8.33 & 85.42 \\
\hline 12 & 4 & 3.92 & 27.45 & 68.63 & 20 & 10 & 20 & 70 \\
\hline 14 & 8 & 6 & 22 & 72 & 32 & 18 & 22 & 60 \\
\hline 15 & 12 & 10 & 34 & 56 & 20 & 15.38 & 50 & 34.62 \\
\hline 16 & 12 & 6 & 26 & 68 & 36 & 15.69 & 29.41 & 54.9 \\
\hline 17 & 12 & 8 & 30 & 62 & 20 & 10 & 32 & 58 \\
\hline 9 & 12 & 12 & 22 & 66 & 32 & 17.65 & 19.61 & 62.74 \\
\hline 11 & 12 & 6 & 38 & 56 & 40 & 18 & 26 & 56 \\
\hline 13 & 12 & 8 & 26 & 66 & 28 & 13.73 & 19.61 & 66.56 \\
\hline 21 & 12 & 9.80 & 13.73 & 76.47 & 24 & 18 & 10 & 72 \\
\hline 23 & 12 & 5.88 & 15.69 & 78.43 & 20 & 10 & 10 & 80 \\
\hline 28 & 12 & 8 & 14 & 78 & 16 & 8 & 14 & 78 \\
\hline 19 & 12 & 5.88 & 21.57 & 72.55 & 24 & 12 & 22 & 66 \\
\hline 5 & 12 & 8 & 18 & 74 & 32 & 15.38 & 19.23 & 65.39 \\
\hline 18 & 16 & 10 & 38 & 52 & 20 & 12 & 36 & 52 \\
\hline 1 & 16 & 9.62 & 19.23 & 71.25 & 28 & 13.73 & 21.57 & 64.70 \\
\hline 3 & 16 & 5.89 & 37.25 & 56.86 & 40 & 23.53 & 19.61 & 56.86 \\
\hline 6 & 16 & 10 & 12 & 78 & 24 & 10 & 6 & 84 \\
\hline 7 & 16 & 11.54 & 23.08 & 65.38 & 24 & 11.76 & 25.49 & 62.75 \\
\hline 20 & 16 & 11.76 & 27.46 & 60.78 & 20 & 15.38 & 26.92 & 57.70 \\
\hline 22 & 16 & 12 & 22 & 66 & 20 & 8 & 14 & 78 \\
\hline 24 & 16 & 6 & 8 & 86 & 24 & 13.46 & 17.31 & 69.23 \\
\hline 25 & 16 & 12 & 14 & 74 & 20 & 11.76 & 23.53 & 64.71 \\
\hline 26 & 16 & 11.76 & 32.47 & 55.77 & 28 & 16 & 26 & 58 \\
\hline 27 & 16 & 12 & 16 & 72 & 20 & 7.69 & 17.31 & 75 \\
\hline 2 & 20 & 12 & 18 & 70 & 40 & 22 & 6 & 72 \\
\hline
\end{tabular}




\section{Note on the karyotype of Dichrop/us pratensis}

This South American grasshopper has a standard karyotype of 19 (XO)/20 (XX) telocentric chromosomes in males and females respectively, upon which a system of seven centric fusions involving the six large autosomes $\left(\mathrm{L}_{1}-\mathrm{L}_{6}\right)$ has been superimposed (Bidau, 1986; Bidau et al., 1991). Populations are unique regarding frequency, quantity and quality of fusions (usually polymorphic). Heterozygotes regularly form trivalents which (as well as fusion bivalents) show altered chiasma patterns (Bidau, 1990) with respect to standard (unfused) bivalents. The alteration, a reduc- tion in chiasma frequency and a shift of chiasmata to distal positions, is related to the maintenance of the polymorphisms in nature (Bidau \& Mirol, 1988; Bidau, 1990, 1991).

The fusions involve telocentrics of very different sizes which, coupled with the variation in chiasma position, allow the comparative study of the incidence of trivalent symmetry on orientation.

\section{Results}

The frequencies of proximal, interstitial and distal chiasmata were scored for each male, and the results are shown in Tables 3-5, along with the mean

Table 4 Percentage of proximal (P), interstitial (I) and distal (D) chiasmata in double heterozygotes of $D$. pratensis. The chiasmata were counted without discriminating between convergent and non-convergent orientation types. The data correspond to PMI and MI stages

\begin{tabular}{|c|c|c|c|c|c|c|c|c|}
\hline \multirow[b]{2}{*}{ Male } & \multicolumn{4}{|c|}{ Metaphase I } & \multicolumn{4}{|c|}{ Prometaphase I } \\
\hline & $\% \mathrm{NCO}$ & $P$ & I & $\mathrm{D}$ & $\% \mathrm{NCO}$ & $P$ & I & D \\
\hline 29 & 12 & 8 & 3 & 89 & 16 & 14 & 7 & 79 \\
\hline 36 & 12 & 7.93 & 38.6 & 53.47 & 30 & 19 & 24 & 67 \\
\hline 37 & 12 & 6.86 & 27.45 & 65.69 & 22 & 12.87 & 31.68 & 55.45 \\
\hline 38 & 12 & 7.77 & 20.39 & 71.84 & 26 & 10.68 & 24.27 & 65.05 \\
\hline 30 & 14 & 12 & 23 & 65 & 36 & 16 & 21 & 63 \\
\hline 34 & 14 & 10.78 & 33.77 & 55.45 & 36 & 18 & 27 & 55 \\
\hline 39 & 14 & 10.89 & 28.71 & 60.40 & 24 & 6.86 & 26.47 & 66.67 \\
\hline 31 & 16 & 14 & 22 & 64 & 34 & 19.80 & 20.79 & 59.41 \\
\hline 35 & 16 & 11.76 & 34.32 & 53.92 & 40 & 21.79 & 26.73 & 51.48 \\
\hline 41 & 16 & 10.89 & 10.90 & 78.91 & 20 & 13.59 & 8.74 & 77.67 \\
\hline 42 & 16 & 14 & 24 & 62 & 36 & 11.76 & 20.59 & 67.65 \\
\hline 32 & 18 & 20.59 & 20.59 & 58.82 & 34 & 15.69 & 20.59 & 63.72 \\
\hline 33 & 18 & 12 & 30.57 & 57.43 & 34 & 20.39 & 26.21 & 53.40 \\
\hline 44 & 18 & 15.84 & 19.80 & 64.36 & 30 & 13.59 & 9.71 & 76.70 \\
\hline 40 & 20 & 14.85 & 20.79 & 64.36 & 32 & 11.65 & 26.21 & 62.14 \\
\hline 43 & 20 & 17.65 & 33.33 & 49.02 & 48 & 22.33 & 37.86 & 39.81 \\
\hline 45 & 20 & 20.80 & 25.73 & 54.47 & 46 & 29.70 & 19.80 & 50.50 \\
\hline
\end{tabular}

Table 5 Percentage of proximal (P), interstitial (I) and distal (D) chiasmata in triple heterozygotes of $D$. pratensis. The chiasmata were counted without discriminating between convergent and non-convergent orientation types. The data correspond to PMI and MI stages

\begin{tabular}{|c|c|c|c|c|c|c|c|c|}
\hline \multirow[b]{2}{*}{ Male } & \multicolumn{4}{|c|}{ Metaphase I } & \multicolumn{4}{|c|}{ Prometaphase I } \\
\hline & $\% \mathrm{NCO}$ & $P$ & I & $\mathrm{D}$ & $\% \mathrm{NCO}$ & $P$ & I & $\mathrm{D}$ \\
\hline 46 & 29.33 & 22.38 & 23.14 & 54.48 & 42.67 & 24.34 & 22.37 & 53.29 \\
\hline 47 & 30.67 & 24.87 & 19.65 & 55.48 & 44 & 25.66 & 23.03 & 51.31 \\
\hline 48 & 34.80 & 27.97 & 21.37 & 50.66 & 46.67 & 28 & 22.67 & 49.33 \\
\hline 49 & 36.10 & 28.95 & 20.39 & 50.66 & 50.67 & 30.46 & 37.36 & 32.18 \\
\hline
\end{tabular}


percentage (based on the scores of 25 cells) of nonconvergent orientation. All V-type orientations (disjunctional) were considered as convergent (CO) and all non-disjunctional ones as non-convergent (NCO). Examples of both types of orientation, as well as the three types of chiasmata, are shown in Fig. 1.

The percentage of NCO for double and triple heterozygotes (Tables 4 and 5) reflects the average of the frequency of $\mathrm{NCO}$ among two or three trivalents respectively (see below).

As males are derived from different localities and years, the parameters under study (chiasmata localization and orientation type) were compared first between localities and between years. All contingency chisquared tests were significant when all the individuals were included (Table 6, A). However, when the analysis was performed for single, double and triple heterozygotes separately, non-significant differences were found (Table 6, B). There were only two exceptions corresponding to orientation type and chiasmata localization for double and triple heterozygotes respectively, both in PMI. These results may indicate a difference in the meiotic behaviour related to the number of trivalents (see below).

As the relationship between the factors that determine trivalent symmetry and orientation could be a multiple linear regression, a one-way ANOvA was first made in order to corroborate this hypothesis. The analysis reveals that a multiple linear regression between the variables explains a significant percentage of the variance $(F=9.402$, d.f. $=3, P<0.0003)$.

The relative importance of each factor (RL, AR and $P$ chiasmata) on orientation was then elucidated through a multiple regression. It was assumed that $\mathrm{P}$ chiasmata should affect orientation more drastically than I ones. Furthermore, in this regression analysis only data from single heterozygotes were included because, first, two out of the three independent variables (AR and RL) characterize a single trivalent and second, in this situation the behaviour of the trivalent is unaffected by interactions with other trivalents.

Table 7 shows the results obtained for PMI and MI.
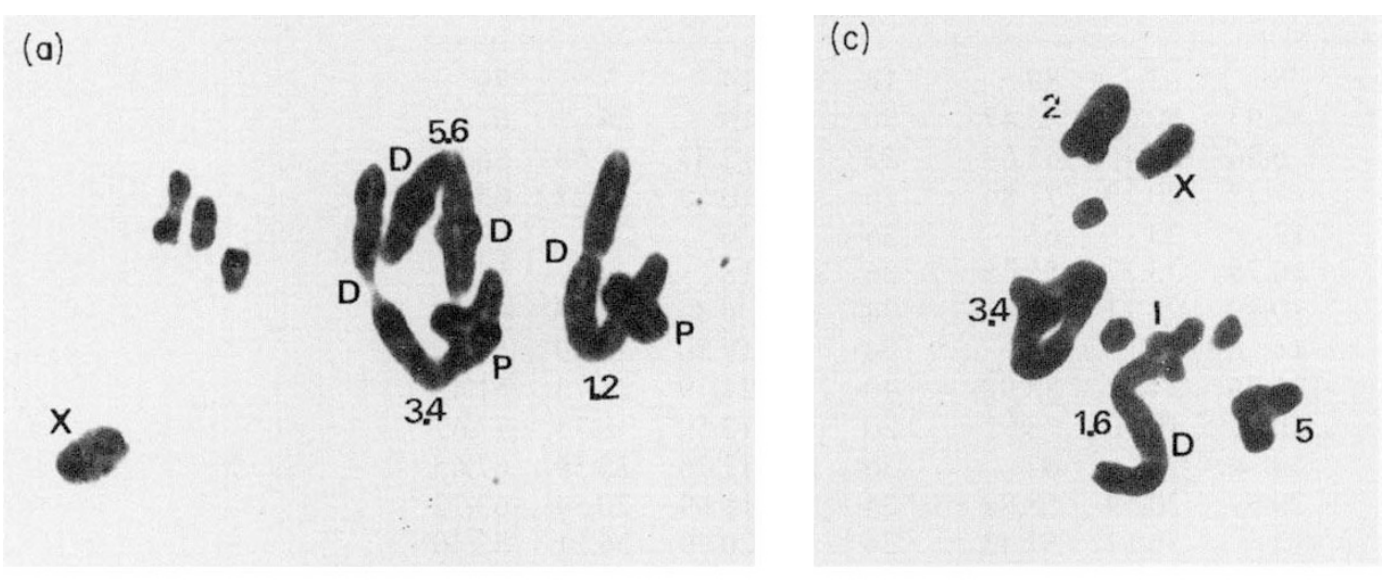

(b)
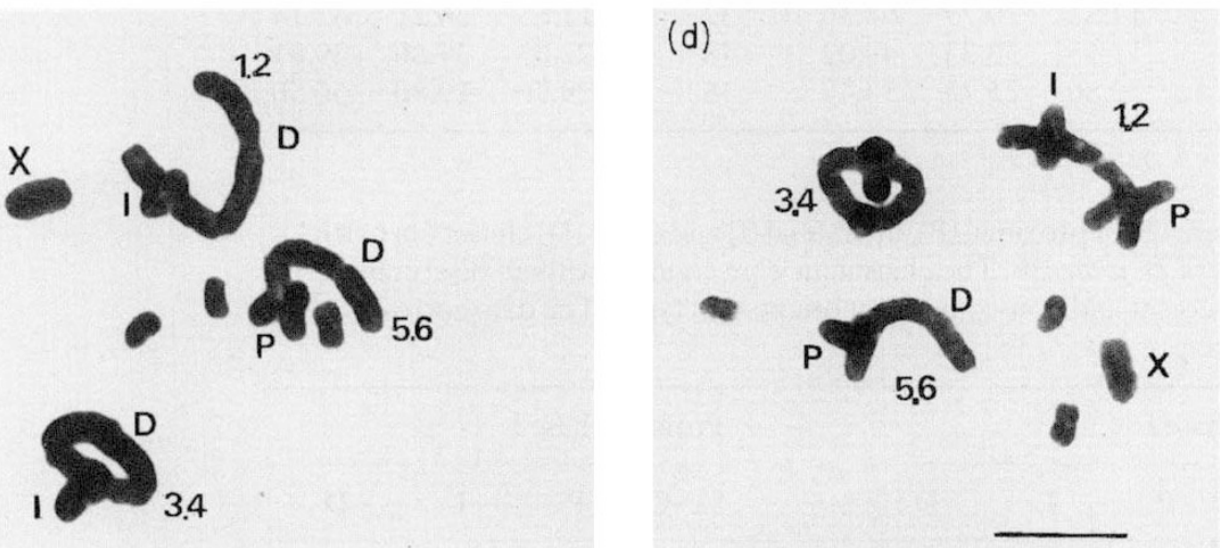

Fig. 1 (a-b) Metaphase I cells with trivalents convergently oriented. (a) 1.2, 3.4, 5.6 triple heterozygote. (b) 1.2, 5.6 heterozygote, 3.4 structural homozygote. (c-d) Prometaphase I cells with trivalents non-convergently oriented. (c) 1.6 heterozygote, 3.4 structural homozygote. (d) 1.2, 5.6 heterozygote, 3.4 structural homozygote. Chiasmata are indicated as: $P$ (proximal), $\mathrm{I}$ (interstitial) and D (distal). Bars represent $10 \mu \mathrm{m}$. 
The regressions are only significant for $\mathrm{P}$ chiasmata, in both stages (PMI: $t=8.348$, d.f. $=24, P<0.00001$; MI: $t=4.498$, d.f. $=24, P<0.0001)$.

These results indicate that in this case, $\mathrm{P}$ chiasma frequency is the predominant factor related to orientation. Even in the extreme case of fusion $1 / 6$, which is the most asymmetrical $(\mathrm{AR}=0.55 \pm 0.02$ ), the size difference between the fused telocentrics does not cause non-disjunctional orientation of the corresponding trivalent. The latter conclusion is supported by the results of contingency chi-squared tests in which frequencies of convergent and non-convergent orientation were compared for the four fusions under study.

Table 6 Results of the chi-squared test for chiasmata localization (Ch: P, I and D) and orientation type (Ot: OC and $\mathrm{NCO}$ ) in PMI and MI stages, between localities and years of capture. (A) Without discrimination between single, double and triple heterozygotes. (B) Simple heterozygotes $(\mathrm{SH})$, double heterozygotes $(\mathrm{DH})$ and triple heterozygotes $(\mathrm{TH})$ separately

\begin{tabular}{|c|c|c|c|c|}
\hline & \multicolumn{2}{|l|}{ Localities } & \multicolumn{2}{|l|}{ Years } \\
\hline & $\mathrm{Ch}$ & Ot & $\mathrm{Ch}$ & $\mathrm{Ot}$ \\
\hline \multicolumn{5}{|l|}{ A } \\
\hline PMI & $186.03^{* *}$ & $65.18^{* *}$ & $55.75^{* *}$ & $21.09^{* *}$ \\
\hline MI & $181.53^{* *}$ & $46.56^{* *}$ & $41.91^{* *}$ & $16.69^{* *}$ \\
\hline \multicolumn{5}{|l|}{ B } \\
\hline \multicolumn{5}{|l|}{$\mathrm{SH}$} \\
\hline PMI & 30.55 & 11.03 & 9.48 & 3.75 \\
\hline MI & 28.46 & 4.64 & 1.33 & 1.47 \\
\hline \multicolumn{5}{|l|}{$\mathrm{DH}$} \\
\hline PMI & 22.43 & $22.03^{*}$ & 7.18 & 0.21 \\
\hline MI & 18.32 & 4.11 & 5.98 & 1.03 \\
\hline \multicolumn{5}{|l|}{$\mathrm{TH}$} \\
\hline PMI & $20.64^{*}$ & 1.12 & 6.72 & 0.79 \\
\hline MI & 2.59 & 1.05 & 1.92 & 1.00 \\
\hline
\end{tabular}

These analyses did not reveal significant differences either in PMI $\left(\chi^{2}=3.36\right.$, d.f. $\left.=3, P>0.05\right)$ or MI $\left(\chi^{2}=4.12\right.$, d.f. $\left.=3, P>0.05\right)$. Thus, all four fusions represent a homogeneous class with respect to orientation, regardless of symmetry of the metacentrics involved. Therefore, the two or three trivalents in double and triple heterozygotes can be averaged for the analysis of the factors that affect symmetry.

The relationship between chiasmata and orientation was then considered the central factor and analysed in depth.

First, the total frequency of P+I chiasmata was analysed with respect to NCO. Both correlations (for PMI and MI) are statistically significant and are shown in Fig. 2a,b (MI: $r=0.495$, d.f. $=48, t=3.907$,
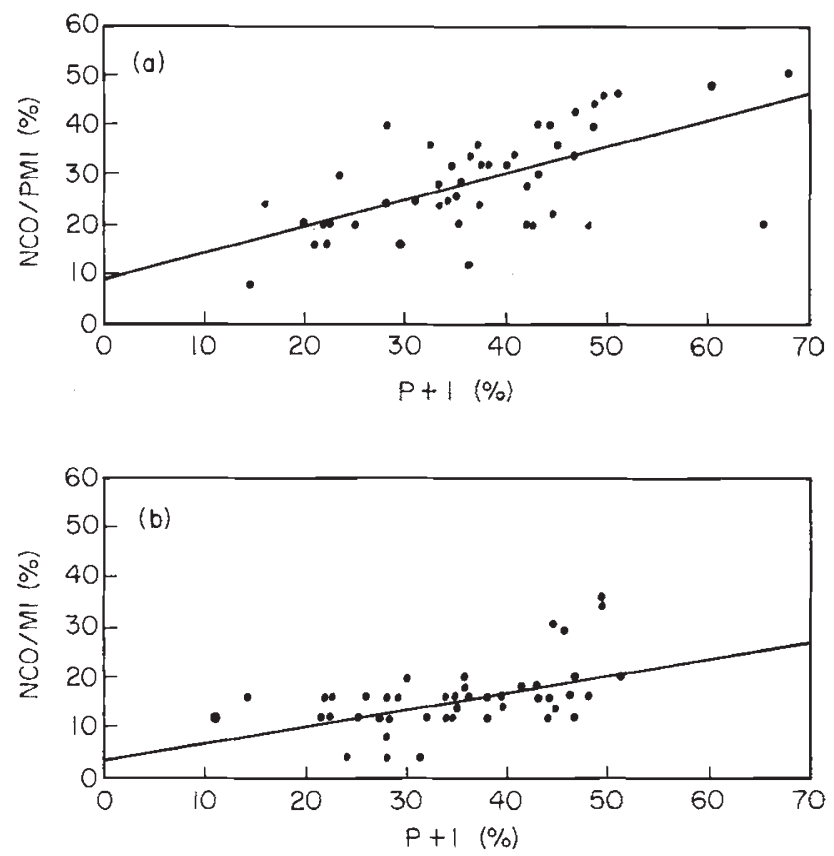

Fig. 2 Relationship between proximal and interstitial chiasmata $(\mathrm{P}+\mathrm{I})$ and NCO in: (a) PMI $(y=8.93+0.54 x$, d.f. $=1$; $48, P<0.001)$ and (b) $\mathrm{MI}(y=3.71+0.34 x$, d.f. $=1 ; 48$, $P<0.001)$.

Table 7 Results of the multiple regression, in PMI and MI, of the frequencies of non-disjunctional orientation and three variables: proximal chiasmata $(\mathbf{P})$, arm ratio $(\mathrm{AR})$ and relative length $(\mathrm{RL})$

\begin{tabular}{llclrl}
\hline Variable & Stage & Coefficient & $\begin{array}{l}\text { Standard } \\
\text { error }\end{array}$ & $t$-value & $\begin{array}{l}\text { Significance } \\
\text { level }\end{array}$ \\
\hline P & PMI & 1.509 & 0.181 & 8.348 & 0.00001 \\
& MI & 1.036 & 0.230 & 4.498 & 0.0001 \\
AR & PMI & 3.578 & 4.162 & 0.859 & 0.3981 \\
& MI & -4.214 & 3.917 & -1.076 & 0.2927 \\
RL & PMI & 0.076 & 0.122 & 0.623 & 0.5389 \\
& MI & 0.071 & 0.152 & 0.468 & 0.644 \\
\hline
\end{tabular}



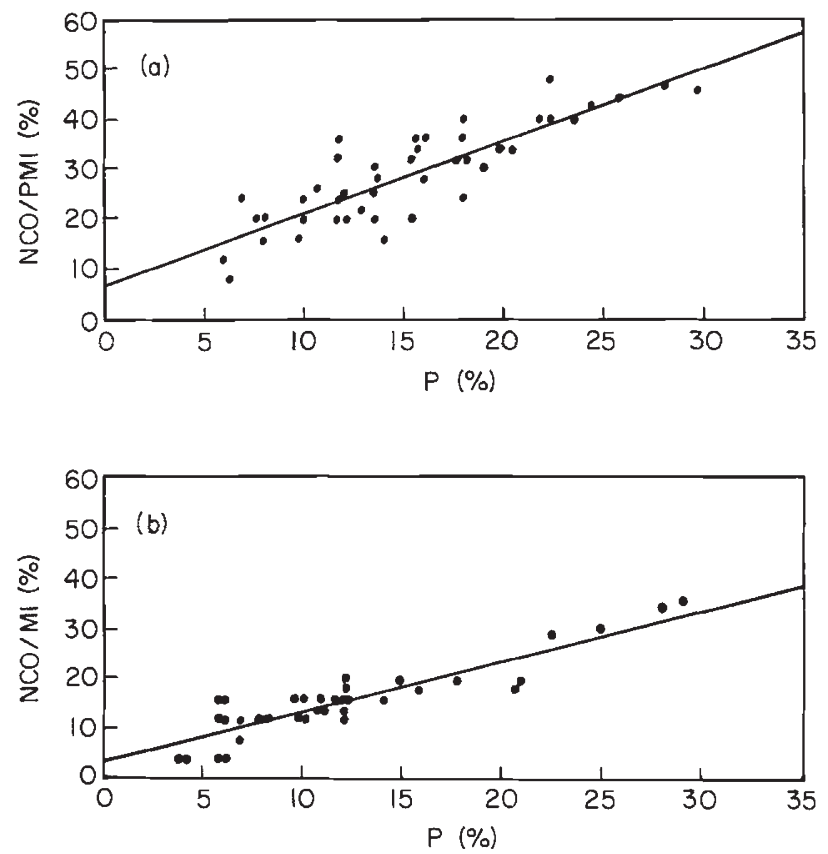

Fig. 3 Relationship between proximal chiasmata and NCO in: (a) PMI $(y=7.25+1.40 x$, d.f. $=1 ; 48, P<0.001)$ and (b) $\operatorname{MI}(y=3.62+1.03 x$, d.f. $=1 ; 48, P<0.001)$.
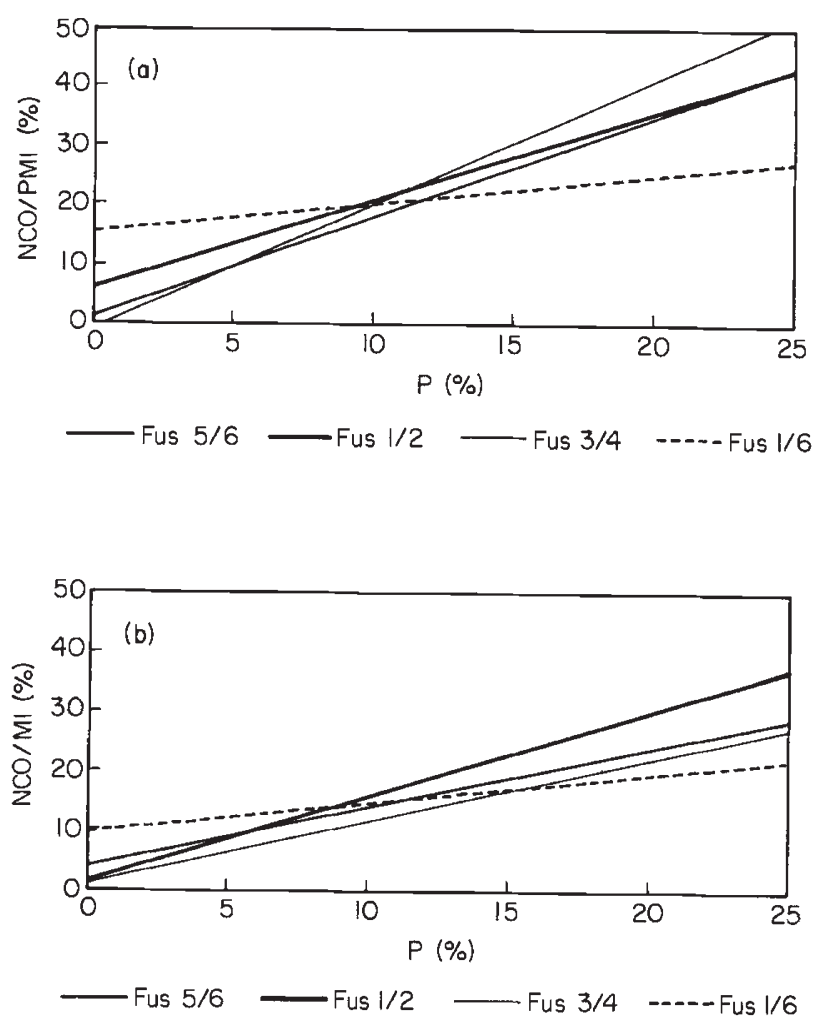

Fig. 4 Relationship between proximal chiasmata and NCO in each fusion separately, at (a) PMI and (b) MI. The correlation equations and their significance are shown in Table 6.
$P<0.001 ; \quad$ PMI: $\quad r=0.619, \quad$ d.f. $=48, \quad t=5.414$, $P<0.001)$. To assess the relative importance of $\mathrm{P}$ and I chiasmata, the same type of analysis was performed separately for each type of chiasma. The correlation between $\mathrm{P}$ and $\mathrm{NCO}$ is highly significant for both stages (Fig. 3a, b) (MI: $r=0.907$, d.f. $=48, t=14.768$, $P<0.001$; PMI: $r=0.869, \quad$ d.f. $=48, \quad t=12.081$, $P<0.001)$. I chiasmata, however, are not correlated to NCO (PMI: $r=0.222$, d.f. $=48, t=1.56, P>0.1$; MI: $r=-0.065$, d.f. $=48, t=0.45, P>0.5$ ).

A regression analysis was then performed for each fusion separately and considering only $\mathrm{P}$ chiasmata (Fig. $4 \mathrm{a}, \mathrm{b}$ ). In all cases the results were statistically significant (Table 8). According to an ANCova test no significant differences exist between the slopes corresponding to each of the four fusions $(F=2.189$, d.f. $=3,23, P>0.05)$. This means that the relationship between P frequency and NCO is the same and independent of the involved fusion or, in other words, that $P$ chiasmata affect trivalent orientation in the same magnitude in all cases.

An alternative approach to analyse the data was to compare the frequency of $\mathrm{P}$ chiasmata in trivalents with $\mathrm{CO}$ and $\mathrm{NCO}$ at MI through an ANOva test in which single, double and triple heterozygotes were included. The analysis shows highly significant differences in $\mathrm{P}$ chiasma frequency between both types of orientation, the frequency always being higher in nonconvergently orientated trivalents $(F=1493.836$, d.f. $=1 ; 188, P<0.0005)$. Significant differences also exist between the three types of heterozygotes (single, double and triple) $(F=12.636$. d.f. $=2,188$, $P<0.0005)$. These results are in agreement with the analysis depicted in Table 6, which shows significant differences between the three types of heterozygotes for chiasmata and orientation. Although these differences could be related to interactions between trivalents in the prophase nucleus (Bidau \& Gimenez, 1990), the interpretation of this result needs further analysis.

Finally, chiasma distribution was compared between stages (PMI and MI). No significant differences were found for $\mathrm{CO}\left(\chi^{2}=0.712\right.$, d.f. $\left.=1, P>0.05\right)$ and $\mathrm{NCO}$ $\left(\chi^{2}=2.815\right.$, d.f. $\left.=1, P>0.05\right)$ trivalents. This is possibly a reflection that chiasma terminalization does not occur in grasshoppers (Tease \& Jones, 1978). Results are shown comparatively in Table 9.

\section{Discussion}

The meiotic system of diploid species has been specifically modelled by natural selection in order to ensure correct pairing and disjunction of homologous chromosomes. It is thus to be expected that complex 
Table 8 Regression equations and their significance between percentages of nonconvergently orientated trivalents of each fusion and frequency of proximal chiasmata, at PMI and MI

\begin{tabular}{|c|c|c|}
\hline Fusion & PMI & MI \\
\hline $1 / 2$ & $\begin{array}{l}y=6.13+1.52 x \\
\text { d.f. }=5, t=39.14, P<0.001\end{array}$ & $\begin{array}{l}y=1.42+1.43 x \\
\text { d.f. }=5, t=21.28, P<0.001\end{array}$ \\
\hline $3 / 4$ & $\begin{array}{l}y=-3.19+2.22 x \\
\text { d.f. }=4, t=28.73, P<0.001\end{array}$ & $\begin{array}{l}y=0.98+1.06 x \\
\text { d.f. }=5, t=10.22, P<0.001\end{array}$ \\
\hline $5 / 6$ & $\begin{array}{l}y=1.39+1.70 x \\
\text { d.f. }=3, t=20.07, P<0.001\end{array}$ & $\begin{array}{l}y=4+x \\
\text { d.f. }=3, t=16.12, P<0.001\end{array}$ \\
\hline $1 / 6$ & $\begin{array}{l}y=13.92+0.66 x \\
\text { d.f. }=8, t=12.19, P<0.001\end{array}$ & $\begin{array}{l}y=9.76+0.49 x \\
\text { d.f. }=8, t=9.53, P<0.001\end{array}$ \\
\hline
\end{tabular}

Table 9 A summary of mean proximal chiasmata number in trivalents oriented convergently and non-convergently $(\mathrm{CO}$ and $\mathrm{NCO}$ ) in simple (SH), double (DH) and triple (TH) heterozygotes of Dichroplus pratensis, at PMI and MI

\begin{tabular}{llll}
\hline & $\mathrm{XP} / \mathrm{SH}$ & $\mathrm{XP} / \mathrm{DH}$ & $\mathrm{XP} / \mathrm{TH}$ \\
\cline { 1 - 3 } $\mathrm{MI}$ & & & \\
$\mathrm{CO}$ & $0.079 \pm 0.036$ & $0.128 \pm 0.062$ & $0.202 \pm 0.048$ \\
$\mathrm{NCO}$ & $0.837 \pm 0.288$ & $0.989 \pm 0.164$ & $1.069 \pm 0.042$ \\
$\mathrm{PMI}$ & & & \\
CO & $0.074 \pm 0.038$ & $0.097 \pm 0.049$ & $0.154 \pm 0.065$ \\
NCO & $0.844 \pm 0.199$ & $0.855 \pm 0.174$ & $1.099 \pm 0.084$ \\
\hline
\end{tabular}

multiple configurations resulting from chromosomal rearrangements in the heterozygous condition, will show impaired meiotic behaviour as the result of the possession of three or more centromeres.

Many factors must be considered to explain the orientation behaviour of a given multivalent (see Introduction). Orientation starts at early prophase I before the centromeres become attached to the spindle fibres. The process can possibly be traced further back to the premeiotic disposition (i.e. Rabl orientation) of chromosomes within the interphase nucleus (Fussel, 1987; Sybenga \& Rickards, 1987; Bidau, 1990; 1991), if these chromosomes retain their telophasic orientation.

Accordingly, pairing and synaptonemal complex formation may predispose the multiple configuration for a given metaphase I orientation (Rickards, 1983).

The orientation of multiples from metaphase I onwards is conditioned to a great extent by the distance that separates different centromeres, which is in turn the result of two factors, namely the size of the chromosomes involved in the multiple and the frequency and, in particular, the localization of chiasmata.

Trivalents and higher order multivalents formed by relatively long chromosomes would be more flexible, a condition that would endow them with greater plasticity for attaining stable orientations (Rickards, 1983; Narasinga Rao \& Sybenga, 1984; Arundathi et al., 1986). In addition, if the size of the multiple is large with respect to spindle size, linear orientations are hardly expected to be stable. Thus, larger chromosomes are in a sense 'preadapted' to orientate disjunctionally when involved in multivalent formation than smaller ones. The currently available evidence is nevertheless far from clear not to say contradictory (Rickards, 1983).

In the case of Dichroplus pratensis all autosomes involved in the fusions belong to the L group (the largest chromosomes of the karyotype). The length differences within this group are not significantly correlated with trivalent orientation at PMI and MI (Table 7). The same can be said of the length ratio of the fused telocentrics (Table 7). It could be assumed that the more similar those lengths, the greater the probability of favourable centromeric interactions within the trivalent leading to disjunctional (convergent) orientation. Data from the available literature in this respect are again ambiguous (Rickards, 1983; Lopez-Fernández et al., 1984).

In $D$. pratensis no significant correlation exists between arm ratio and trivalent orientation. Nevertheless this could be due to the reasons discussed above: even in the case of fusion $1 / 6$ (the most asymmetrical one), differences in arm length are perhaps not sufficiently large to become relevant factors in orientation.

Symmetry of the multiple is, however, most affected by chiasmata because from diplotene onwards they determine the effective inter-centromeric distances and thus, the ultimate symmetry of the configuration. Once again, available data and hypotheses are contradictory (Rees \& Sun, 1965; Sybenga, 1975; Rickards, 1977, 1983; Wise \& Rickards, 1977; de Boer \& van Beek, 1982; Diez \& Puertas, 1984; Cabrero \& Camacho, 
1985; Arana et al., 1987; Parker, 1987; Bidau, 1990). According to the tension hypothesis, a given orientation is stable when forces exerted by spindle fibres upon a centromere are balanced against opposite forces that operate on a centromere connected to the first one (Sybenga, 1975; Rickards, 1983; Narasinga Rao \& Sybenga, 1984; Sybenga \& Rickards, 1987). This hypothesis, along with others that involve an order of centromeric activation (which consider each centromere activation an independent event), are the basis of a model for centromeric co-orientation of trivalents developed by Narasinga Rao \& Sybenga (1984).

Proximal chiasmata and, to a lesser degree, interstitial ones, shorten inter-centromeric distances, which in turn would determine the mode of association of neighbouring centromeres to spindle fibres, the tension exerted upon them and the possibility of independent activation, establishing their orientation to the same or opposite poles.

In a reciprocal translocation spontaneous mutant of Euchorthippus pullvinatus gallicus, in which a large and a medium-size chromosome are involved, Arana et al. (1982) reported a certain relationship between interstitial chiasma formation and disjunctional orientation. Similar results were reported for a mutant of Eyprepocnemis plorans; in this case interstitial chiasmata impede adjacent 2 orientation (Arana et al., 1982). These results support their hypothesis that the stabilization of a multivalent is the result of a competition between its centromeres to attain a certain tension which could be acquired more easily when the distance between them is shorter. Thus, interstitial and proximal chiasmata would favour co-orientation of adjacent centromeres.

However, note that chiasmata formation in interstitial segments of translocation multivalents (i.e. the segments between the centromeres and the sites of exchange) is relevant for the formation of the maximum multiple, a previous requirement for disjunctional orientation and balanced segregation (Rickards, 1983; John, 1987). This, but not the proximity of centromeres, could be the cause of the above observations.

de Boer and van Beek (1982), however, provide convincing data to support the opposite hypothesis, which maintains that proximal chiasmata render adjacent centromeres more susceptible to orientation towards the same spindle pole. In his study of interchange trisomic mice, the frequency of proximal chiasmata and adjacent 2 segregation is reduced with respect to parental lines. Hence, proximal chiasmata would tend to render adjacent centromeres to function as a unit that orientates towards the same pole. The latter agree with traditional opinion that the greater the number and the more proximal the chiasmata in the multivalent, the less able are orientation forces to effect a zigzag configuration (John, 1987).

Our results support the hypotheses of de Boer \& van Beek (1982). First, the presence of univalents is very infrequent, which implies that, at least, two chiasmata were formed regularly. Then, the formation of a maximum multiple is guaranteed. Second, a strong positive correlation exists between the frequency of proximal chiasmata and non-convergent orientation in all trivalents (Fig. 4a and b). This result is consistent with the idea that it is more probable that a given kinetochore associates with the closer spindle pole (Sybenga \& Rickards, 1987). The kinetochores of centromeres that are close owing to the presence of a proximal chiasma would be thus connected to the same pole.

The four studied fusions are not significantly different with respect to the relationship between proximal chiasmata and orientation, which suggests that this relationship is independent of the chromosomes involved in each fusion.

Note that the former correlation holds for proximal but not for interstitial chiasmata. There thus probably exists a critical minimum inter-centromeric distance regarding orientation. Distances below this minimum would determine interactions of centromere pairs leading to non-disjunctional orientations.

A further relevant factor is multivalent reorientation. As non-convergent orientations are not always necessarily stable: a centromere may lose its connection with one of the poles if the forces imposed upon it by the spindle fibres are not balanced. Then it may associate with fibres projecting from the opposite pole (Sybenga, 1975; Sybenga \& Rickards, 1987). Thus, extrapolations about disjunction from metaphase I data should not be conclusive.

Our results confirm the effect of chiasma localization on trivalent orientation, which is of importance regarding the polymorphisms in which the fusions of Dichroplus pratensis are involved. The former are balanced and stable (Mirol \& Bidau, 1991).

Thus no drastic decrease in fertility due to nondisjunctional segregation is expected in heterozygotes. Such segregation is as demonstrated, strongly influenced by proximal chiasmata. Indeed, in polymorphic populations of $D$. pratensis, a significant decrease in proximal chiasmata occurs in fusion heterozygotes and homozygotes but not in standards (Bidau, 1990, Tosto \& Bidau, 1991) which suggests that the fusions per se exert this effect. This redistribution of crossover sites is of central importance for the maintenance of the polymorphisms. First, linkage and elimination of proximal recombination favour linkage disequilibria and preservation of co-adapted gene complexes (Bidau, 1990; 1991). Second, our results directly imply that lowered 
chiasma frequencies in fusion heterozygotes (involving elimination of proximal chiasmata) make disjunctional segregation easier, which is a basic cytogenetic precondition for the stability of a chromosomal polymorphism.

Hence, proximal chiasmata that occur somewhat infrequently in fusion heterozygotes of $D$. pratensis induce non-disjunctional segregation and unbalanced gametes. Thus, their elimination by an inherent effect of the fusions (Bidau, 1991) would be adaptative not only because it allows convergent orientation and balanced segregation of a favourable chromosome and gene combination but because preservation of coadapted supergenes due to suppression of recombination might occur.

\section{Acknowledgements}

We are grateful to Dr J. Hunziker for critical reading of the manuscript. We would like to thank Dr E. Hasson and Lic A. Papesci, whose helpful suggestions are included in the paper. Thanks are also due to Lic D. Tosto for collection of some material and helpful comments. The continuous support of CONICET is acknowledged. Part of the paper was produced while P. Mirol was guest of the Universidad Nacional de Misiones.

\section{References}

ARANA, P., HENRIQUes-Gil, N. AND SANTos, J. L. 1987a. Orientation behaviour of interchanges forming chiasmata in interstitial regions: A cytological approach. Heredity, 58, 15-24.

ARANA, P., SANTOS, J. L. AND HENRIQUES-Gil, N. 1987b. Interference relationships in grasshopper reciprocal translocation heterozygotes. Heredity, 59, 85-93.

ARANA, P., SANTOS, J. L., HENRIQUES-GIL, N. AND GIRALDEZ, R. 1982. Centromere co-orientation in a spontaneous translocation heterozygote of Euchorthippus pulvinatus gallicus (Acrididae, Orthoptera). Genetica, 58, 81-84.

ARUNDHATI, A., NARASINGA RAO, P. S. R. L. AND SYBENGA, J. 1986. Possible causes of variation in trivalent orientation frequencies in pearl millet and rye. Genetica, 70, 81-87.

BAKER, R. J. AND BICKHAM, J. w. 1986. Speciation by monobrachial centric fusions. Proc. Natl. Acad. Sci. U.S.A., 83, 8245-8248.

BIDAU, C. J. 1986. Geographic distribution of chromosome polymorphism in Dichroplus pratensis Bruner (Melanoplinae, Acrididae) in Argentina. In: Proceedings of the 4th Triennial Meeting of the Pan American Society, pp. 165-166.

BIDAU, C. J. 1989. Zonas hibridas en ortopteros: el ejemplo de
Dichroplus pratensis (Acrididae). In: Proceedings I Congreso Argentino de Entomologia Tucuman, Republica Argentina, (ed.) Sociedad Argentina de Entomologia, pp. 109-124.

BIDAU, C. J. 1990. The complex Robertsonian system of Dichroplus pratensis (Melanoplinae, Acrididae). II. Effects of the fusion polymorphisms on chiasma frequency and distribution. Heredity, 64, 145-159.

BIDAU, C. J. 1991. Multivalents resulting from monobrachial homologies within a hybrid zone in Dichroplus pratensis (Acrididae): meiotic orientation and segregation. Heredity, 66, 219-232.

BIDAU, C. J., BELINCO, C., MIROL, P. M. AND TOSTO, D. s. 1991. The complex Robertsonian system of Dichroplus pratensis (Melanoplinae, Acrididae). I. Geographic distribution of fusion polymorphisms. Selection, Genetique. Evolution, 23, 353-370.

BIDAU, C. J. AND GIMENEZ, M. D. 1990. Orientación y segregación meióticas en heterocigotas estructurales: un modelo basado en la orientación de Rabl. In: Proceedings XXI Congreso Argentino de Genética, Entre Rios, República Argentina, (ed.) Sociedad Argentina de Genética, pp. 58.

BIDAU, C. J. AND MIROL, P. M. 1988. Orientation and segregation of Robertsonian trivalents in Dichroplus pratensis (Melanoplinae, Acrididae). Genome, 30, 947-955.

CABRERO, J. AND CAMACHO, J. P. M. 1985. A spontaneous interchange heterozygote mosaic in the grasshopper Stauroderus scalaris: interchromosomal chiasma effects. Heredity, 54, 235-243.

CANO, M. I. AND SANTOS, J. L. 1990. Chiasma frequencies and distributions in gomphocerine grasshoppers: a comparative study between sexes. Heredity, 64, 17-23.

DE BOER, P. AND VAN BEEK, M. E. A. B. 1982. Meiosis of T70H translocation trisomic male mice. I. Meiotic configurations and segregation. Chromosoma, 87, 303-313.

DIEZ, M. AND PUERTAS, M. J. 1984. Interchromosome effects on chiasma distribution due to translocations in Locusta migratoria. Genetica, 63, 189-194.

FUSSEL, C. P. 1987. The Rabl orientation: a prelude to synapsis. In: Moens, P. B. ed., Meiosis, Academic Press, New York. pp. 275-299.

JOHN, B. 1987. The orientation behavior of multiple chromosome configurations in acridid grasshoppers. Genome, 29, 292-308.

KING, M. 1987. Chromosomal rearrangements, speciation and the theoretical approach. Heredity, 59, 1-6.

LOPEZ-FERNANDEZ, C., RUFAS, J. S., GARCIA DE LA VEGA, C. AND GOSAlvez, J. 1984. Cytogenetics studies on Chorthippus jucundus (Fish.) (Orthoptera) III. The meiotic consequences of a spontaneous centric fusion. Genetica, 63, 3-7.

MIROL, P. M. AND BIDAU, C. J. 1991. Meiotic behavior of Robertsonian heterozygotes in populations of Dichroplus pratensis (Acrididae) with different fusion frequencies. Genetica, 84, 171-178.

NARASINGA, RAO, P. S. R. L. AND SYBENGA, J. 1984. Linear orientation of trivalents and quadrivalents in late metaphase I pollen mother cells of pearl millet. Can. J. Genet. Cytol. 26, 506-510. 
PARKER, J. S. 1987. Increased chiasma frequency as a result of chromosome rearrangement. Heredity, 58, 87-94.

REES, H. AND SUN, S. 1965. Chiasma frequency and the disjunction of interchange associations in rye. Chromosoma, 16, 500-510.

RICKARDS, G. K. 1977. Prometaphase I and anaphase I in an interchange heterozygote of Allium triquetrum (Liliaceae). Chromosoma, 64, 1-23.

RICKARDS, G. K. 1983. Orientation behavior of chromosome multiples of interchange (reciprocal translocation) heterozygotes. Ann. Rev. Genet., 17, 443-498.

SITES, J. W. JR. AND MORITZ, c. 1987. Chromosomal evolution and speciation revisited. Syst. Zool. 36, 153-174.

sybengA, J. 1975. Meiotic Configurations. Springer-Verlag, Berlin.

SYBENGA, J. AND RICKARDS, G. K. 1987. The orientation of multi- valents at meiotic metaphase I: a workshop report. Genome, 29, 612-620.

TEASE, C. AND JONES, G. H. 1978. Analysis of exchanges in differentially stained meiotic chromosomes of Locusta migratoria after BrdU substitution and FPG staining. I. Crossover exchanges in monochiasmata bivalents. Chromosoma, 69, 163-178.

TOSTO, D. S. AND BIDAU, C. J. 1991. Distribution of chromosome frequencies within a hybrid zone of Dichroplus pratensis (Melanoplinae, Acrididae). Heredity, 67, 299-307.

White, M. J. D. 1978. Modes of speciation. W. H. Freeman \& Co., San Francisco.

WISE, D. AND RICKARDS, G. K. 1977. A quadrivalent studied in living and fixed grasshopper spermatocytes. Chromosoma, 63, 305-315. 